\section{NOVA TELLVS}

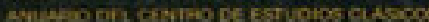

Nova Tellus

ISSN: 0185-3058

novatelu@servidor.unam.mx

Centro de Estudios Clásicos

México

RAMÍREZ VIDAL, Gerardo

Notas sobre la retórica de Isócrates

Nova Tellus, vol. 24, núm. 1, 2006, pp. 157-178

Centro de Estudios Clásicos

Distrito Federal, México

Disponible en: http://www.redalyc.org/articulo.oa?id=59114742008

- Cómo citar el artículo

- Número completo

- Más información del artículo

- Página de la revista en redalyc.org

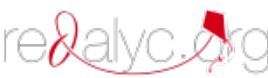

Sistema de Información Científica

Red de Revistas Científicas de América Latina, el Caribe, España y Portugal

Proyecto académico sin fines de lucro, desarrollado bajo la iniciativa de acceso abierto 


\title{
Notas sobre la retórica de Isócrates
}

\author{
Gerardo RAMÍREZ VIDAL \\ Universidad Nacional Autónoma de México \\ grvidal@servidor.unam.mx
}

RESUMEN: En este trabajo se presentan algunos temas centrales de la retórica isocratea que deben ser tomados en consideración para un estudio profundo de su técnica retórica en que se basaba su labor pedagógica. Se aborda en primer lugar la concepción que Isócrates tenía de su propia disciplina y la existencia de un probable manual teórico suyo, se continúa con su concepción pragmática del lenguaje y del objeto de la retórica, y se concluye con la presentación de otros temas importantes: la invención, los géneros retóricos, los principios, la memoria y la acción oratoria.

\begin{abstract}
$* * *$
ABSTRACT: This paper presents a few central themes of the rhetoric of Isocrates that should be taken into consideration in a detailed study of the rhetorical theory in which his pedagogy was based. First, Isocrates' thoughts about his own discipline are examined, as well as the probable existence of a theoretical manual of his; then, his pragmatic idea of the language and purpose of rhetoric are taken into consideration. The paper concludes with the presentation of other important themes: invention, genres of rhetoric, principles, memory, and rhetorical action.
\end{abstract}

PALABRAS ClAVE: discurso, Isócrates, paideia, retórica.

RECEPCIÓN: 23 de marzo de 2006.

ACEPTACIÓn: 7 de abril de 2006. 



\title{
Notas sobre la retórica de Isócrates
}

\author{
Gerardo RAMÍREZ VIDAL
}

\section{Los estudios sobre la retórica isocratea}

El ateniense Isócrates, discípulo de los sofistas y, en particular, de Gorgias de Leontini, cuya vida casi centenaria abarcó del 436 al 338 a. C., ha sido considerado como "el representante más destacado de la retórica", ${ }^{1}$ o como "el más famoso maestro del discurso en el mundo antiguo", según el título de un artículo sobre él. ${ }^{2}$ Marrou afirma que, en términos generales

fue Isócrates y no Platón el educador de la Grecia del siglo iv y, después de ella, del mundo helenístico primero, y romano más tarde: de Isócrates salieron, "como de un caballo de Troya" [Cic., De or., II, 94] aquellos innumerables pedagogos y literatos [...] a quienes la antigüedad clásica adeuda, así en buenas cualidades como en defectos, toda la esencia de la tradición cultural. [...] es a Isócrates, mucho más que a cualquier otro, a quien le cabe el honor y la responsabilidad de haber inspirado la educación predominantemente literaria de nuestra tradición occidental. ${ }^{3}$

Estas reflexiones de Marrou ponen en evidencia la importancia de aquel gran pedagogo de la política.

Los notables estudios de personajes como Jaeger y Marrou, dieron nuevo brío a los estudios sobre Isócrates, pero la aten-

\footnotetext{
${ }^{1}$ Jaeger, p. 830.

${ }^{2}$ Goodwin, 1959.

${ }^{3}$ Marrou, p. 96.
} 
ción que se le ha dedicado a nuestro orador ha seguido sobre todo la línea trazada por Jaeger quien considera a Isócrates como "el padre de la cultura humanística", aun cuando el estudioso observaba que "lo que los educadores modernos consideran no pocas veces como la esencia del 'humanismo' es, sustancialmente, la continuación de la línea retórica de la cultura antigua". ${ }^{4}$ A pesar del papel central que supuestamente jugó Isócrates en la enseñanza de la retórica, la atención que se ha brindado al objeto, las partes, las relaciones entre éstas $\mathrm{y}$, en resumen, al contenido de su disciplina, es muy pobre. Tal parece que, debido al dominio que ha ejercido Platón en los estudios del pensamiento griego, a la enorme influencia de la Retórica aristotélica y al propio desprestigio de la retórica, Isócrates, en cuanto rhétor, ha sido relegado al rincón, pagando caro así su oposición a los socráticos de su tiempo.

Generalmente se destaca que la enseñanza retórica de Isócrates no se limitaba a la instrucción retórica, que esto sería empobrecer su enseñanza, reducirla a lo que él se oponía: a una simple sistematización de los medios de persuasión para vencer en los tribunales o en los debates políticos. Su enseñanza era mucho más amplia: era la Paideia, la formación cultural del ciudadano. En otras palabras: la retórica era simple instrumento de la educación y de la cultura, o cuando más, una parte de ella. Se reproduce así, tal vez inconscientemente, el repudio a la retórica por los propios estudiosos de esta disciplina. En este caso, Marrou expuso la enseñanza de la retórica como el coronamiento de los estudios, como la educación superior de los jóvenes, ${ }^{5}$ aun cuando a ello dedica poco más de una página, sin esbozar siquiera el sistema retórico de Isócrates.

Richard Leo Enos, por su parte, escribió en 1993 un libro sobre la retórica griega antes de Aristóteles, pero, en el caso

\footnotetext{
4 Jaeger, p. 832.

${ }^{5}$ Marrou, pp. 101-102.
} 
de Isócrates, se contenta con referirse en general a su sistema educativo, sin entrar propiamente en el tema de la naturaleza, objeto y partes de la retórica. Al mayor rhétor de la Antigüedad le dedica sólo cinco páginas en un libro enfocado a la retórica prearistotélica, mientras que Platón, quien ha sido considerado como el mayor adversario de la retórica, recibe un tratamiento cinco veces mayor, cosa que, sin embargo, no es extraña en los estudios contemporáneos. Takis Poulakos publicó en 1997 un libro sobre la educación retórica en Isócrates intitulado Speaking for the Polis, aunque esta obra no tiene el objetivo de abordar directamente la retórica isocratea, sino el más amplio de la educación, siendo la retórica una parte de ella. Dos años después, en 1999, Schiappa publicó otro libro sobre los inicios de la teoría retórica en la Grecia clásica, y también Robert G. Sullivan ha trabajado sobre algunos aspectos centrales de la retórica de Isócrates. ${ }^{6}$ Pero como podrá notarse en todas estas publicaciones, sigue haciendo falta un trabajo sistemático y de conjunto sobre la retórica en Isócrates.

En resumen, me parece que el rhetorical turn que se dio desde hace medio siglo ha permitido poner en el centro de la atención la importante e interesante figura de Isócrates, sobre todo en la última década, pero el interés se ha enfocado particularmente a profundizar en la naturaleza y el carácter pedagógico y político de su obra, que son aspectos centrales sobre su contribución en la historia de la cultura occidental, mientras que el propio sistema retórico ha sido estudiado sólo parcialmente.

\footnotetext{
${ }^{6} \mathrm{Cf}$., por ejemplo, Sullivan, 2001. Otros autores que abordan aspectos directamente relacionados con la retórica son Wagner, 1922; Goodwin, 1959, y Benoit, 1990 y 1991. Schiappa, por su parte, aborda el por demás interesante asunto de qué es lo que realmente Isócrates pretendía enseñar. Las páginas que le dedica a Isócrates son clarificadoras, pero no aborda directamente el problema de la retórica o "filosofía de los discursos" de Isócrates (sobre el problema del concepto de "filosofía" cf. infra).
} 


\section{La filosofía retórica}

Debe subrayarse desde el inicio que Isócrates nunca empleó la palabra "retórica" para referirse a su enseñanza, sino el de "filosofía" (o paideia). ${ }^{7}$ Isócrates, según Jaeger, no empleaba el término "filosofía" en sentido platónico, sino tal como era entendida entonces, gracias a la herencia sofística, esto es, como formación general del ciudadano frente a la formación especializada o a los dogmas o los métodos planteados, por ejemplo, por Platón y su escuela.

La palabra filosofía no tenía, en Isócrates, el sentido de "amor por la sabiduría", sino que se refería a una destreza práctica o "habilidad", o a la formación o preparación orientada a alcanzar esa habilidad o pericia, cuyo fin último, en el caso de Isócrates, era el bien de la polis. ${ }^{8}$ Esto puede desprenderse del pasaje donde Isócrates afirma: "considero sophoí a quienes son capaces, mediante las opiniones, de lograr lo óptimo la mayoría de las veces y philósophoi a quienes se dedican

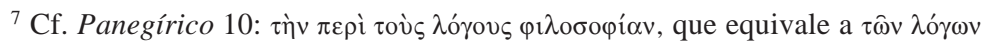
$\pi \alpha 1 \delta \varepsilon i ́ \alpha$ de Antídosis, 180, passim. Los demás sofistas, excepto Alcidamante, tampoco emplearon el término retórica. De cualquier modo habrá que señalar que Isócrates emplea con frecuencia la palabra $\tau \varepsilon ́ \chi v \eta$ para referirse al arte del discurso, en particular del discurso judicial. Véase por ejemplo: Trapezítico, 2; Contra los sofistas, 15 (donde indica específicamente el arte de polemizar y elaborar discursos), 19 (se refiere en general a las artes escritas por los antepasados); $A n$ tídosis, 179 (indica indirectamente que su enseñanza es un arte que tiene semejanza con otras), Antídosis, 181 (Isócrates llama a su arte "filosofía"), etcétera.

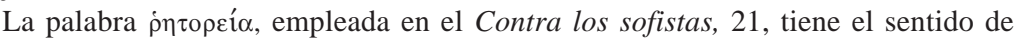
"oratoria", "retoricidad", aunque se han dado traducciones muy diferentes (cf. Schiappa, 1999, p. 158).

${ }^{8}$ La palabra $\varphi$ í $\lambda$ os era empleada en los compuestos con el valor de un prefijo

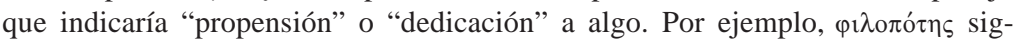
nifica "quien es propenso a beber", es decir, "bebedor", "borracho"; фı $\lambda$ óvıко ,

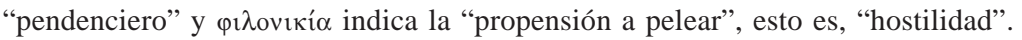
Ahora bien, esta philosophía, en cuanto "propensión a la habilidad" o "dedica-

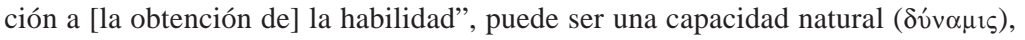
un arte $(\tau \dot{\varepsilon} \chi \vee \eta)$ o una experiencia y hábito.
} 
a aquello a partir de lo cual rápidamente obtienen ese saber práctico". ${ }^{9}$ De tal modo, la filosofía isocratea era esencialmente una filosofía linguiística pragmática, e Isócrates debería ser considerado como uno de los filósofos del lenguaje más representativos en la historia de la filosofía. ${ }^{10}$

Además, habrá que observar que Isócrates consideraba que la suya era la auténtica filosofía, no la de Platón que estaba orientada a especulaciones metafísicas sin aplicación práctica en la vida política, y rechazaba que la enseñanza platónica pudiera ejercer ese alto rol educativo que este filósofo se había propuesto alcanzar; a Platón y su escuela los considera erísticos, esto es, simples polemistas, y refuta el núcleo de la enseñanza, esto es, la existencia de verdades generales y únicas, frente a la verdadera existencia de opiniones contingentes y mutables, cuyo consenso y certidumbre daba origen a las decisiones adoptadas, además, obviamente, de la inutilidad de la filosofía de los socráticos.

En consecuencia, en sentido estricto él no sería un "maestro de retórica" (rhétor), sino un "filósofo" del discurso, pero no con el sentido que ahora le damos a la palabra "filósofo". Sin embargo, Platón y Aristóteles denominaron la paideia isocrática como "retórica", en un sentido peyorativo, sobre todo en el caso del primero, esto es, como una retórica viciosa, dañina y defectuosa, aunque también ellos enseñaban retórica, pero se trataba de una "retórica" virtuosa, buena y justa. La denominación platónico-aristotélica triunfó sobre la de Isócrates, y

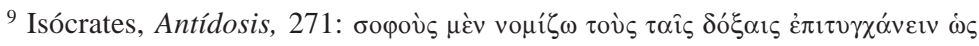

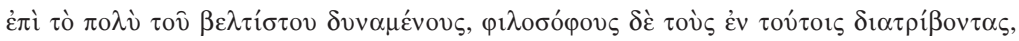

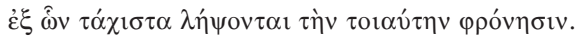

${ }^{10}$ Isócrates fue un filósofo tal como los pragmáticos actuales son filósofos (por ejemplo, R. Rorty); sin embargo, no aparece tratado así tradicionalmente, y se ha optado por ignorarlo. Schiappa observa (1999, p. 164) que ni siquiera aparece Isócrates en la Encyclopedia of Philosophy, que se proponía cubrir la totalidad de la filosofía y rescatar del olvido figuras injustamente olvidadas. Además, los traductores de Isócrates a menudo prefieren traducir la palabra $\varphi \imath \lambda_{0}-$ бофía como "retórica".
} 
a ello se debe que ahora consideremos como retórica la enseñanza de Isócrates y de los sofistas.

Como sería desorientador emplear la palabra "filosofía" para referirnos a la enseñanza de Isócrates, seguiremos empleando la etiqueta que le impusieron Platón y su escuela, en vez de otras palabras que podrían ser más apegadas a la doctrina sofística, como logología o discursividad, pero que no se encuentran acreditadas. ${ }^{11}$ Obviamente, el empleo de la palabra "retórica" provoca un equívoco, pues el significante no corresponde al significandum. Pero esto es tan frecuente que no debería preocuparnos demasiado. Así, emplearemos la palabra "retórica" para designar la filosofía discursiva isocratea, aun cuando tenga un sentido que etimológicamente no le corresponde. $^{12}$

Habiendo, pues, admitido identificar a Isócrates como un rhétor, ${ }^{13}$ entendido este término en el sentido de "maestro de

\footnotetext{
${ }^{11}$ Habrá que puntualizar que Isócrates no utiliza la palabra $\varphi \imath \lambda$ inopí $\alpha$ en vez de retórica, sino más bien que Platón llamó "retórica", en sentido peyorativo, a lo que Isócrates llamaba "filosofía". Yo empleo la palabra "retórica" para referirme a la "filosofía de los discursos" de Isócrates, en el entendido de que: a) la retórica no es una disciplina secundaria en relación con la filosofía, sino por lo menos de la misma jerarquía; b) la retórica es una disciplina filosófica del lenguaje persuasivo donde la verdad no es lo real, sino que ésta se debe entender como "una creencia que obedece a nuestros propósitos prácticos" (Rorty); c) se debe distinguir entre filosofía y retórica en cuanto a que la finalidad de ambas no es la misma, y en que la primera es una reflexión de la muerte (Fedón) y la segunda lo es de la vida; y d) Isócrates entendía la palabra "filosofía" en términos distintos al sentido platónico y actual de filosofía. En fin, dejemos a la filosofía ser el tribunal de la razón y la columna de la verdad apodíctica y absoluta; retribuyamos a la retórica el sentido crítico y la conciencia de que la opinión y las creencias gobiernan las relaciones humanas y permiten la relación entre los hombres.

${ }^{12}$ En términos generales, el problema consistiría en definir el sentido doctrinal de la palabra "retórica", pero esta tarea también es inalcanzable, pues los autores antiguos y modernos privilegian sentidos diferentes, e inclusive opuestos, de modo que llamaremos "retórica", en un sentido técnico formal muy general, a la disciplina o las disciplinas del discurso persuasivo, y en su sentido material, a la dimensión persuasiva del lenguaje.

${ }^{13} \mathrm{El}$ propio Isócrates niega que sea un rhétor, en Filipo, 81, y en la Carta,
} 
retórica", debemos también admitir que, a diferencia de los demás maestros de retórica de su tiempo, no consideraba la retórica (esto es, su "filosofía de los discursos) como simple instrumento de persuasión, como simple técnica de la palabra, sino como el fin o la meta educativa que él perseguía. Del mismo modo, así como no se debe pensar en el lenguaje como un instrumento del pensamiento, sino más bien como una entidad que da forma al pensamiento, así también debe considerarse la filosofía isocratea como una dimensión que organiza nuestro juicio y expresión en la práctica política.

Obviamente, tampoco le era de utilidad la "retórica" tal como era presentada por Platón y, por otro lado, como era concebida por Alcidamante, esto es, como un simple adiestramiento orientado a adquirir suficiente destreza para persuadir al destinatario, sin plantearse ni altas miras ni una moral. Isócrates necesitaba refundar la retórica (esto es, la "filosofía de los discursos"), darle un nuevo estatuto con nuevos principios, redefinir sus partes, reorientando sus fines, fijándole temas generales (ideai), adaptándole una nueva estructura discursiva, y, fundamentalmente, poniendo a la altura de los altos fines el poder del lenguaje. Se trató de una renovación profunda en todos los sentidos, pero ello lo llevó a olvidarse de los problemas cotidianos del hombre común, a despreciar los pleitos judiciales y a aborrecer a los oradores políticos cargados de pasiones, de egoísmos y de vicios. En ese sentido no sólo las ideai platónicas resultaban ejercicios inútiles para el ciudadano, sino también las suyas: al elevarse perdió contacto con la realidad. Sin embargo, su enseñanza tuvo frutos importantes también en el ámbito práctico. De hecho, toda la retórica judicial posterior a él fue influida por su enseñanza, según el parecer de los estudiosos.

8.7, pero en ambos casos tiene el sentido común de "orador" o "político", no de maestro del discurso. 


\section{El sistema retórico según Navarre}

Como hemos dicho, los mecanismos de la "retórica" isocratea casi no se han estudiado. El único, hasta donde sé, que ha surcado de manera sistemática en el terreno de la técnica retórica de Isócrates es Octave Navarre en su fundamental y célebre estudio sobre la retórica griega anterior a Aristóteles, publicado en el lejano año de 1900. El ilustre profesor analiza con gran tacto el sistema retórico a partir de las fuentes antiguas, observando primero las limitaciones de su enseñanza, pues la naturaleza del discípulo y la práctica eran aspectos más importantes que la misma teoría en la tarea del educador: quienes no tenían dotes naturales no podían llegar a ser grandes oradores. Luego analiza los fundamentos de la retórica y sus partes (esto es, la técnica retórica propiamente). Al final termina haciendo una valoración sobre el papel que jugó el gran rhétor ateniense en la cultura de su tiempo.

Sin embargo, e independientemente del valor indudable de ese estudio, Navarre adoptó en su descripción los principios, el esquema y la terminología de la retórica basada en Aristóteles, sin tomar en consideración que la "retórica" de Isócrates tenía características muy particulares, como sucede, por poner un ejemplo, con la división de los discursos en géneros: judicial, deliberativo y epidíctico. Esta clasificación constituye un intento exitoso por poner orden en las clasificaciones que se habían estado elaborando sin criterios definidos, pero también significa una reducción del campo de la disciplina retórica a un ámbito que, según el Gorgias platónico, era ilimitado. No sólo la descripción de géneros debería elaborarse a partir de los propios datos que al respecto encontramos en el escritor, sino en general, todos los elementos de la retórica deberían estudiarse con base en lo formulado por el propio autor y en sus propios ejemplos discursivos. 


\section{El manual retórico de Isócrates}

Navarre logró describir la retórica isocratea basándose en los discursos del sofista que contienen frecuentes pasajes donde se abordan los fundamentos y el objeto de esa disciplina. Se basó también en los fragmentos de un supuesto manual de retórica que aparecía bajo el nombre de Isócrates en las fuentes antiguas. ${ }^{14}$ No sería extraño que el mayor rhétor de la Antigüedad hubiera escrito una obra del género, aunque no necesariamente debía titularse como Arte retórica. Ya antes los maestros de retórica (según la tradición platónico-aristotélica) y los sofistas griegos del siglo v, aquellos que habían inventado una retórica entendida como disciplina, habían elaborado esos manuales técnicos típicos (llamados posteriormente "artes retóricas") dirigidos a la enseñanza del arte de persuadir. Corax y Tisias compusieron entre ambos un manual en el que exponían sus enseñanzas sobre la persuasión, o tal vez cada cual hizo el suyo, y lo mismo hicieron los sofistas Gorgias, Antifonte y Teodoro; Lisias también elaboró un arte. Seguramente hubo muchos manuales escritos durante la segunda mitad del siglo v y la primera del IV, y uno de ellos pudo haber sido elaborado por Isócrates.

En efecto, Aristóteles publicó un sumario o un resumen de los manuales que hasta entonces se habían escrito sobre retórica en una obra intitulada Colección de artes. Según una biografía isocratea de autor anónimo, en esa colección se mencionaba un manual de retórica atribuido al maestro. ${ }^{15}$ Debe suponerse entonces que Isócrates había escrito dicho manual, que circulaba en Atenas y en la Roma de la época de Quintiliano (quien no estaba seguro de su atribución). Aunque no se

\footnotetext{
${ }^{14}$ Aparecen entre los fragmentos del $T L G$, en la edición teubneriana (Mandilaras, 2003, vol. III).

${ }^{15}$ Cf. Vita Isocratis, 151.
} 
crea a pies juntillas que Demóstenes hubiera aprendido el Arte de Isócrates en secreto, como refiere Plutarco en su Vida de Demóstenes (5.5), de cualquier modo esa historia presupone la real existencia de un arte atribuido al maestro. También podría dudarse de que Isócrates no hubiera querido recibir a Demóstenes por no haber tenido éste la suma para pagar el curso completo. También Cicerón, quien había tenido en sus manos el sumario de Aristóteles, ${ }^{16}$ pudo haber tenido el original, pues afirma que Isócrates, luego de haberse empleado en la logografía, se dedicó por completo a escribir artes retóricas. ${ }^{17}$ En este caso ya no se habla de uno, sino de varios tratados, y en efecto, Isócrates habría escrito otras obras del género, pues en la vida del pseudo Plutarco se afirma que había colaborado con Terámenes, uno de sus maestros, en la elaboración de algunos tratados de retórica, probablemente para que Terámenes se defendiera de las acusaciones políticas fabricadas en su contra; esas obras se conocían como Escritos de Boton. ${ }^{18}$

Sin embargo, ya en la Antigüedad algunos dudaban de que hubiera publicado algún tratado, pues el maestro no se basaba en la teoría sino en la práctica. ${ }^{19}$ Los autores modernos han encontrado diversos detalles que permiten dudar de la autenticidad de esta $\tau \dot{\varepsilon} \chi v \eta$. Primero, en la Antigüedad no había consenso en atribuir la obra a Isócrates, como se puede colegir de Quintiliano, quien duda precisamente de que la Ars que él conocía pudiera adscribirse a Isócrates: "si es que el arte que circula es de veras suya". ${ }^{20}$ Pero lo único que prueba esto es que se dudaba de que la obra fuera auténtica. Segundo, ha

\footnotetext{
${ }^{16} \mathrm{Cf}$. De inventione, II, 7.

${ }^{17}$ Cicerón, Bruto, XII, 48: totumque se ad artes componendas transtulisse.

${ }^{18}$ Pseudo Plutarco, Vida de Isócrates, 3.

${ }^{19} \mathrm{Cf}$. Vida de Isócrates, 32.

${ }^{20}$ Institutio retorica, ii, 15.4, cf. III, 1.14: si tamen re uera ars quae circumfertur eius est.
} 
resultado curioso que hubiera escrito una obra semejante, si se toma en cuenta el desprecio con que él se refiere a los compositores de las así llamadas "artes retóricas" en su tratado Contra los sofistas ( $\$ 19)$. Pero no puede darse demasiado peso a esta observación, pues Isócrates también negaba haberse dedicado a la logografía, cosa que sí había hecho. Tercero, Isócrates tampoco menciona haber compuesto una $\tau \dot{\varepsilon} \chi v \eta$, y, si se considera su vanidad y tendencia a la autoalabanza, no habría estado dispuesto a pasarla en silencio. Pero si él realmente no apreciaba esa obra no tendría ningún motivo para mencionarla. Cuarto, los pocos fragmentos que se conservan de esa obra difieren de los discursos en el aspecto estilístico, como el nulo cuidado que tiene por evitar el hiato. Se podría argumentar que la obra no fue elaborada para su publicación.

De cualquier modo, parece seguro que en la Antigüedad hubiera realmente circulado un tratado sobre el arte de la persuasión que Aristóteles consideró como un manual de retórica, razón por la cual lo expuso en su Colección de artes, y que los autores tardíos lo habían conocido como una obra de Isócrates, aunque no era del todo seguro. Quienes han supuesto que la obra no era suya, piensan que lo más probable es que lo fuera de alguno de sus discípulos, o tal vez, como sugiere Navarre siguiendo a Pfund y Rehdantz, ${ }^{21}$ que ésa contuviera las notas del curso del maestro tomadas y publicadas por uno de los discípulos. De cualquier modo, sea como haya sido, la obra contenía la enseñanza del maestro, y en efecto, lo poco que de ella se conserva coincide con lo que sabemos directamente de Isócrates, como sucede en el caso de la naturaleza de la retórica. Sin embargo, debemos subrayar que muy probablemente esa obra no fue intitulada "Manual de retórica", sino que fue así considerada y conocida por los autores posteriores.

Otra cosa cierta es que no podemos aspirar siquiera a reconstruir el tratado original, sino sólo a ordenar, a partir de

${ }^{21}$ Cf. Blass, 1887-98, II, p. 96. 
criterios isocrateos, las ideas sobre los diferentes principios y elementos retóricos empleados en su enseñanza, su orden y su vinculación, sobre todo a partir de lo que él mismo dice en su obra, en particular en los discursos donde expone su teoría, como en el Contra los sofistas o en la Antídosis, y a partir de lo que resta del manual que, si no era suyo, sí lo era de su escuela. Es necesario asumir la existencia de una teoría retórica o logológica de Isócrates, y que no sería un ejercicio inútil tratar de reconstruirla. Pero para reconstruir esta $\tau \dot{\varepsilon} \chi v \eta$ isocratea deberíamos necesariamente evitar ser influidos por Aristóteles, en cuyo esquema se basa Navarre. De esta manera, con la expresión $\tau^{\prime} \chi v \eta \eta$ nos referiremos no a un manual concreto, sino, en general, a su teoría sobre el arte de la palabra.

\section{El himno al logos}

Isócrates concibe el lenguaje no como un medio de comunicación o de información, sino como un acto de habla retórico, y observa el lenguaje no como lo observaría un lingüista o un gramático, sino como lo observaría un experto pragmático.

Que el lenguaje es un medio de adhesión y cohesión era algo claro para Isócrates, quien expresó la valoración más profunda que haya existido sobre el logos en la Grecia antigua, pero como observaremos lo hizo de una manera muy especial. En su obra intitulada Nicocles, datada en el 368, observa (III, 5-9) que los hombres somos inferiores a los demás seres vivos en cuanto

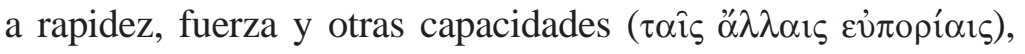
pero en cambio superamos a las bestias en cuanto poseemos la capacidad de persuadirnos mutuamente y de manifestarnos a nosotros mismos nuestros deseos. ${ }^{22}$ Gracias a esta capacidad,

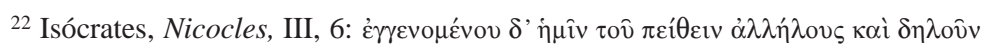

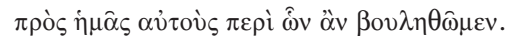


a diferencia de los animales, podemos congregarnos y levantar ciudades, establecer normas e inventar las artes. Y agrega Isócrates: "casi todo lo que hemos ideado el logos nos ha ayudado a establecerlo". ${ }^{23}$ Aquí observamos una reformulación de lo que ya antes Protágoras había expuesto en el mito de Prometeo sobre el origen de la cultura y las artes, aunque Isócrates pone el logos como el generador y creador de los cambios, no como un producto.

Además de las instituciones que se han creado con el logos, éste estableció las leyes que nos permiten convivir los unos con los otros. El logos es el instrumento de la educación y la manifestación misma del intelecto. "Con él discutimos sobre asuntos discutibles e investigamos las cosas desconocidas", 24 y explica en seguida que todo esto lo realizamos cuando hablamos gracias a los medios que utilizamos para atraernos la confianza o la fe, esto es, gracias a las pisteis. ${ }^{25}$ Isócrates termina diciendo:

Y si es necesario hablar resumidamente acerca de esta capacidad, no encontraremos ninguna acción realizada con inteligencia que no sea hecha sin el concurso de la palabra, sino que de todas nuestras acciones e ideas el logos es el guía, y más lo utilizan quienes poseen el mayor intelecto. ${ }^{26}$

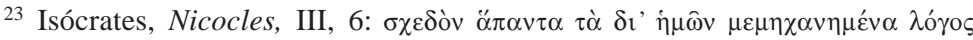

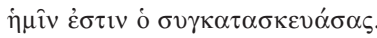

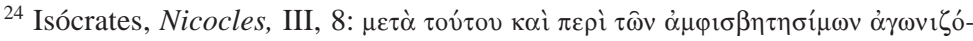

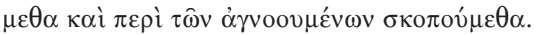

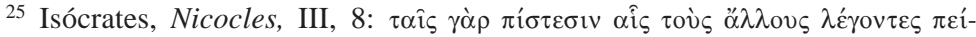

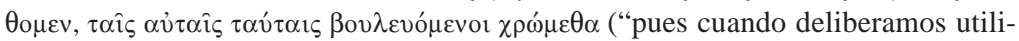
zamos las mismas pisteis con las que persuadimos a los demás cuando hablamos").

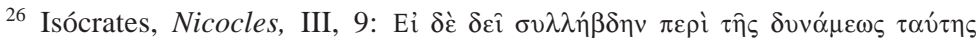

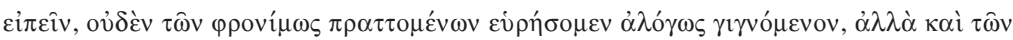

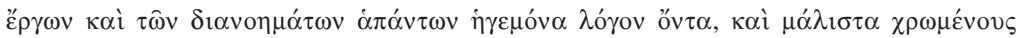

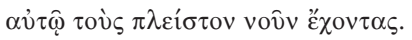




\section{El logos como acto de habla retórico}

El logos o lenguaje es visto como una facultad ergástica, esto es, productiva, en cuanto sirve para producir, e inclusive es personificado, en cuanto es él el que legisla y es él el guía (i $\gamma \varepsilon \mu o ́ v \alpha)$ de nuestras acciones y de nuestros pensamientos. En términos modernos, Isócrates estaría hablando de los actos de habla ilocucionarios y perlocucionarios. Aparece evidente que no se está hablando de estas virtudes de la palabra como algo accesorio, sino como su propia esencia. A diferencia de nuestra concepción de la función comunicativa del lenguaje, Isócrates no menciona nunca esta función, puesto que la comunicación no es una finalidad del lenguaje. En síntesis, el logos es un acto de habla retórico, está preñado de retoricidad. Es claro que ya desde Homero la palabra constituye el motor de los cambios, y que era muy conocida la comparación del fármaco con la medicina. Gorgias expresaba que el logos con un cuerpo pequeñísimo creaba obras maravillosas. Isócrates sigue en esta misma línea, aun cuando la relación la establezca más con lo que él creía verdaderamente importante, esto es, con la vida social organizada, convirtiendo a la retórica en una disciplina del discurso que guía hacia una acción concertada en beneficio de la polis. ${ }^{27}$ Isócrates es el rhétor político por excelencia. Su instrumento son los actos de habla retóricos.

\section{El objeto de la retórica}

Como la palabra logos es demasiado general, Isócrates emplea un término técnico para referirse específicamente a los medios de adhesión (llamados pisteis); es gracias a ellos que persuadimos o nos atraemos a los demás por medio del lenguaje,

\footnotetext{
${ }^{27}$ Poulakos, 1997, pp. 10 ss.
} 
como aparece en el citado "Himno al logos": las pisteis. En la Antídosis se dice, por ejemplo, que

¿Quién en efecto, no sabe que los discursos que parecen más verdaderos son aquellos pronunciados por personas apreciadas y no por quienes están desacreditadas, y que las pisteis más poderosas son las que provienen de la vida más que las que son procuradas por el discurso, de modo que en la misma medida que uno desee persuadir con más fuerza a sus oyentes más se ejercitará en ser noble y estimado por los ciudadanos. ${ }^{28}$

Por una parte aquí trata del êthos y, por otra, se refiere a los medios de adhesión referidos al êthos, que es más o menos lo mismo que dirá después Aristóteles. Los medios de adhesión más persuasivos son aquellos que provienen de la persona, no los que provienen del discurso, esto es, no los medios lógicos. Una buena imagen es mejor que un buen argumento. Luego Isócrates ${ }^{29}$ continúa señalando que quienes se dedican a la philosophía saben muy bien cómo atraerse la benevolencia de los oyentes, y menciona los eikota y los tekmêria entre toda una especie de pisteis que son los instrumentos que ayudan al orador en su actividad discursiva. ${ }^{30}$

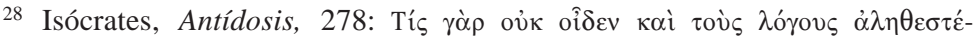

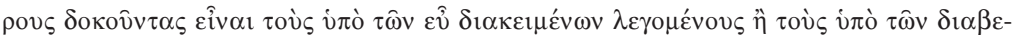

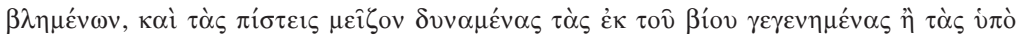

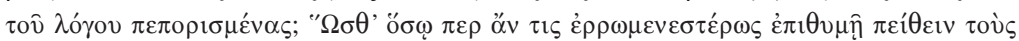

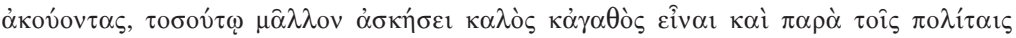

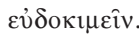

${ }^{29}$ Cf. Antídosis, 279-280.

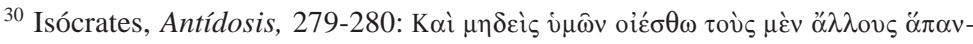

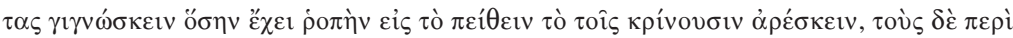

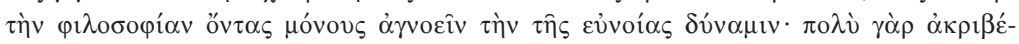

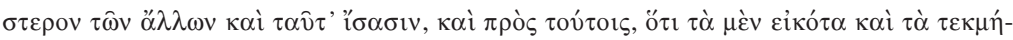

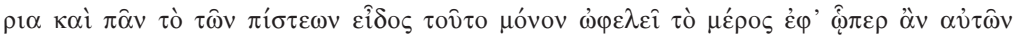

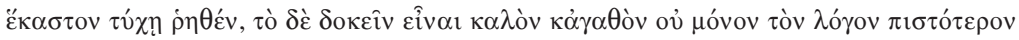

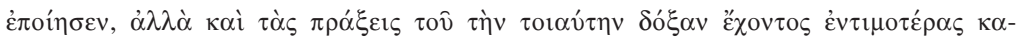

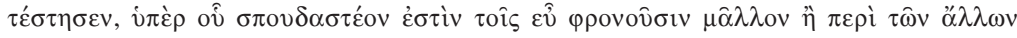
$\dot{\alpha} \pi \alpha ́ v \tau \omega v$. 
Encontramos aquí una clasificación de las pisteis o medios de adhesión que ya aparece, por ejemplo, en Antifonte, y que después será empleada por Aristóteles, aunque con sentidos más específicos. Además de los eikota y de los tekmêria, en otro pasaje se incluyen los sêmeia. ${ }^{31}$

\section{El papel del ornato}

La lexis es la parte más desarrollada de los estudios sobre Isócrates desde que Dionisio de Halicarnaso expusiera sutilmente las cualidades del estilo. Entre las virtutes elocutionis, de las cuales no trataré aquí, el empleo de las figuras, del ritmo, de la armonía musical, etcétera, reciben un tratamiento singular. Sin embargo, todos estos efectos del estilo, vistos en su particularidad pierden la esencia de su ser. Nada más alejado del pensamiento de Isócrates que el ornato por el ornato mismo. Para el sofista, el discurso en su conjunto tiene una función, un ergon, y también las diferentes ideai o especies tienen su propia función dentro del conjunto armónico del discurso. Las minucias estilísticas tienden a crear las cualidades del estilo: claridad, precisión, pureza y belleza, y éstas, a su vez, tienden a dar al discurso el poder persuasivo buscado por el autor. En su discurso Filipo (5), Isócrates señala que había enseñado a sus discípulos a escribir "con simetrías y variaciones para hacer los discursos más dulces y más convincentes". Las figuras existen en tanto instrumento de persuasión. Ahora bien, en su época esto era muy conocido por todos: a nadie se le habría ocurrido embellecer por embellecer; pero en nuestra época, el predominio de la idea del arte por el arte ha oscurecido la antigua concepción pragmáticoretórica del estilo y, en particular, de las figuras. Como este

\footnotetext{
${ }^{31}$ Cf. Panegírico, 104, donde aparece al lado del tekmêrion.
} 
asunto ha sido estudiado de manera óptima por Takis Poulakos, reenviamos a él para una exposición más completa.

\section{Conclusiones}

Los estudios sobre la retórica o filosofía del discurso isocratea, en sentido estricto, son muy pobres. Fuera de las observaciones generales sobre su enseñanza y de la descripción puntual de Navarre, poco es lo que se ha avanzado en este campo, y esto ha sucedido bajo la influencia determinante de Aristóteles. Habrá que seguir abordando problemas puntuales y de conjunto, tratando de seguir en este último caso la línea borrosa que va de los sofistas a Anaxímenes de Lámpsaco, no aquella de Platón-Aristóteles.

En el caso de los puntos teóricos y prácticos, el trabajo de los estudiosos debería dirigirse a una serie de temas de primer orden. Por ejemplo, uno de los aspectos mejor elaborados por Isócrates es el relativo a la invención, que se encuentra visualizada en el pasaje ya citado de la Antídosis, 189, dentro de lo que parecería ser el esquema general de las partes de la retórica: "quien tiene el alma capaz de descubrir, aprender, trabajar y memorizar y la voz y la claridad de expresión [...]". ${ }^{32}$ Por lo menos la invención, la memoria y la acción parecen tener sus lugares tradicionales en el proceso retórico.

Es cierto que para Isócrates la invención cae en el dominio de las capacidades naturales y de la práctica, de manera que no es posible saber aprehender los argumentos apropiados a cada caso. ${ }^{33}$ Pero este principio no impide el desarrollo de una

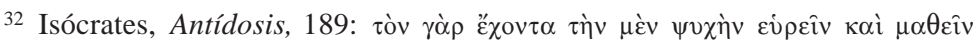

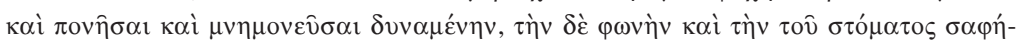
$v \varepsilon 1 \alpha v[\ldots]$

${ }^{33}$ Cf. Antídosis, 181, 256.
} 
teoría sobre este punto. Isócrates observa una característica del lenguaje que es central en la parte de la invención.

Los logoi tienen una naturaleza tal que es posible narrar las mismas cosas de muchas maneras, hacer insignificantes las cosas grandes y engrandecer las pequeñas, exponer de manera novedosa las cosas antiguas y hablar acerca de los acontecimientos contemporáneos al viejo estilo [...] Yo creo que todas las artes y entre éstas la filosofía retórica, harían un gran progreso si se admirase y honrase no a quienes han iniciado las primeras de estas artes sino a quienes han llevado a cabo de la mejor manera cada una de ellas; no a quienes buscan hablar de cosas de las que nadie antes ha hablado sino a quienes saben hablar de una manera como nadie lo podría hacer. ${ }^{34}$

Esta es la esencia de la invención, que consiste no sólo en encontrar argumentos nuevos, sino también en encontrar la manera óptima de expresarlos. Uno de los fragmentos de la $\tau \dot{\varepsilon} \chi \vee \eta$ perdida contenía precisamente esta afirmación isocratea de que la función de la retórica es engrandecer lo pequeño y empequeñecer lo grande, y decir lo nuevo con palabras viejas y lo viejo con palabras nuevas. ${ }^{35}$

Hasta donde sé, el punto de la invención no ha sido abordado.

Otro problema importante es el de los géneros. La tendencia a emplear en este caso los géneros aristotélicos empobrece

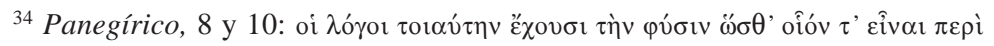

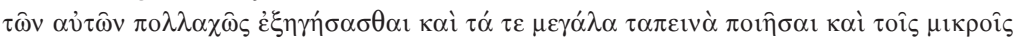

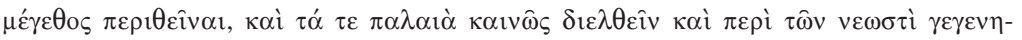

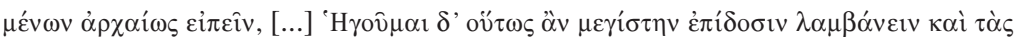

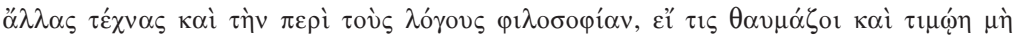

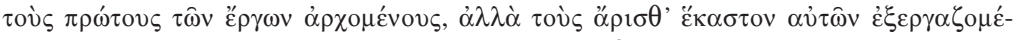

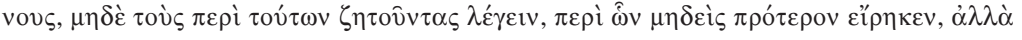

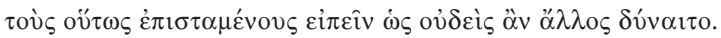

${ }^{35}$ Cf. Máximo Planudes, V, p. 455, 1, en Walz, et Joannes Siceliota, Rhetores

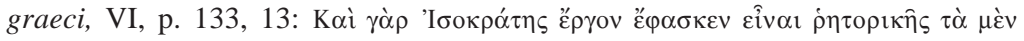

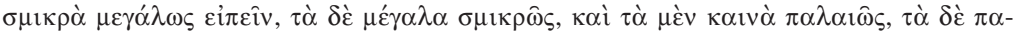

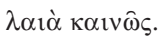


enormemente el campo de la aplicación de la retórica. Una tendencia actual de los estudios sobre esta disciplina es la retórica política, y en Isócrates encontramos un campo muy rico, y casi virgen. Deberán abordarse también los conceptos del kairós y de to prepon, centrales en la enseñanza retórica; aunque han sido estudiados, no aparecen integrados de manera sistemática en la retórica de Isócrates. En efecto, Navarre los pasa por alto. Lo mismo podría decirse de la memoria, de la actio, de los tipos de pisteis, etcétera.

No tiene poca importancia conocer los mecanismos de la retórica isocratea, y debería emprenderse la tarea de estudiarlos de manera sistemática. Sobre todo si creemos seriamente que él fue sin duda el rhétor por excelencia de la Antigüedad.

\section{BIBLIOGRAFÍA}

BenoIT, W., "Isocrates and Aristotle on Rhetoric", en Rhetoric Society Quarterly, 20, 1990, pp. 251-260.

- "Isocrates and Plato on Rhetoric and Rhetorical Education", en Rhetoric Society Quarterly, 21, 1991, pp. 60-72.

Blass, F., Die attische Beredsamkeit, 3 vols., Leipzig, 1887-1898. Vol. II, "Isokrates und Isaios", 1892.

Enos, Richard Leo, Greek Rhetoric before Aristotle, Illinois, Waveland, 1993.

Goodwin, B., "Isocrates of Athens: Foremost speech teacher of the Ancient World", en Speech Teacher, 8, 1959, pp. 251-255.

Isocrate, Discours, texte étab. et trad. G. Mathieu and É. Brémond, Paris, "Les Belles Lettres", 1972.

-, Orazioni, intr., trad. e note Ch. Ghirga e R. Romussi, Milano, BUR, 1993.

Isocrates, Opera omnia, 3 vols., edidit B. G. Mandalaras, Monachi et Lipsiae, Saur, Verlag, 2003.

JAEger, W., Paideia. Los ideales de la cultura griega, México, Fondo de Cultura Económica, 1974.

Kennedy, G., The art of persuasion in Greece, Princeton, University Press, 1963.

MANDILARAS, cf. ISOCRATES. 
Marrou, H.-I., Historia de la educación en la Antigüedad, Buenos Aires, Eudeba, 1970.

Navarre, O., Essai sur la rhetorique grecque avant Aristotle, Paris, Achette, 1900.

Poulakos, T., Speaking for the Polis. Isocratis' Rhetorical Instruction, Columbia, University Of South Carolina, 1997.

SchiApPa, E., The beginnings of Rhetorical Theory in Classical Greece, New Haven, Yale University Press, 1999.

Sullivan, R. G., "Eidos, Idea in Isocrates", en Philosophy and Rhetoric, 34, 2001, pp. 79-92.

Wagner, R., “The Rhetoric Theory of Isocrates”, en Quarterly Journal of Speech Education, 8, 1922, pp. 323-337. 